\title{
Genetic Analysis of Radiation-sensitive Mutations in the Slime Mould Dictyostelium discoideum
}

\author{
By D. L. WELKER AND R. A. DEERING \\ Biophysics Laboratory, Department of Biochemistry and Biophysics, \\ The Pennsylvania State University, Pennsylvania 16802, U.S.A.
}

(Received 6 April 1976)

\begin{abstract}
SUMMARY
The linkage of two mutations leading to increased sensitivity to ultraviolet light and ${ }^{60} \mathrm{Co}$ gamma rays was determined in the slime mould Dictyostelium discoideum using a genetic analysis based on the parasexual cycle. Diploids were selected from a mixture of radiation-sensitive, temperature-resistant and radiation-resistant, temperature-sensitive haploids on the basis of simultaneous radiation and temperature resistance. Analysis of drug-resistant haploid segregants of the heterozygous diploids indicated that one of the radiation-sensitive mutations, $\operatorname{radA2o}$, was linked to linkage group I whereas the other, $\operatorname{radBr} 3$, was linked to the recently defined linkage group VI.
\end{abstract}

\section{INTRODUCTION}

The response of the cellular slime mould Dictyostelium discoideum to ultraviolet (u.v.) light and ${ }^{60} \mathrm{Co}$ gamma rays and also to monofunctional and bifunctional alkylating agents has been studied previously (Deering, I968; Freim \& Deering, 1970; Deering et al., 1970; Payez, Deering \& Freim, I972). Mutants have been isolated on the basis of increased sensitivity to gamma rays. These also display large differences in sensitivity to u.v. light and alkylating agents (Deering et al., 1970). Evidence suggests that these differences are the result of differing abilities to repair, enzymically, lesions produced in the DNA of cells exposed to these agents (Deering et al., 1970; Payez \& Deering, 1972; Deering \& Jensen, 1973; Khoury \& Deering, I973; Deering, I975; Guialis \& Deering, 1976a, b).

In order to study repair of damage to DNA in this eukaryote, it was desirable to obtain genetic information on the radiation-sensitive mutants. To date, genetic analysis of $D$. discoideum has been based on a model of the parasexual cycle (Pontecorvo \& Käfer, I958). The most fruitful approach has been to isolate temperature-resistant diploids following fusion of two haploid amoebae bearing non-allelic temperature-sensitive mutations (Loomis, 1969; Katz \& Sussman, 1972). If the parental haploids contain recessive drug-resistant mutations, then haploid drug-resistant segregants can be selected from the heterozygous, drug-sensitive diploid population (Katz \& Sussman, 1972). Mutations can be assigned to linkage groups on the basis of their segregation into the drug-resistant haploids, since haploidization is thought to occur via transient aneuploidy involving random chromosome loss (Sinha \& Ashworth, 1969; Brody \& Williams, 1974).

Most of the radiation-sensitive mutations in $D$. discoideum have been isolated in strain NC4, a commonly used temperature-resistant wild-type strain. Therefore, diploids could not be selected solely on the basis of temperature-resistance without prior selection of temperature-sensitive strains from each of the radiation-sensitive strains to be studied. However, this problem was circumvented by selecting diploids on the basis of simultaneous radiation

Volume 96, No 2, was issued 28 October 1976 
Table I. Description of haploid Dictyostelium discoideum strains used

\begin{tabular}{|c|c|c|c|c|c|c|c|c|}
\hline \multirow[b]{2}{*}{ Strain } & \multirow[b]{2}{*}{ Parent } & \multicolumn{7}{|c|}{ Genotype* } \\
\hline & & $c y c A I$ & $\operatorname{rad} A 20$ & $w h i$ & $\operatorname{acr} A r$ & tsg DI2 & $\operatorname{man} A I$ & $\operatorname{radBI} 3$ \\
\hline $\mathrm{NC4}$ & & + & + & + & + & + & + & + \\
\hline XMI & DMWI & - & + & - & - & - & - & + \\
\hline$\gamma \mathrm{s} 20$ & $\mathrm{NC} 4$ & + & - & + & + & + & + & + \\
\hline$\gamma \mathrm{SI} 3$ & NC4 & + & + & + & + & + & + & - \\
\hline HPSI & DPSIT & + & - & - & - & - & - & + \\
\hline HPS3 & DPS I & + & - & - & - & - & + & + \\
\hline HPS7 & DPSI & - & + & - & - & - & - & + \\
\hline HPS8 & DPS I & - & + & - & - & - & + & + \\
\hline HPS9 & DPS2 & - & + & - & - & - & - & + \\
\hline HPSIO & DPS2 & + & + & - & - & - & - & + \\
\hline HPSI I & DPS2 & + & + & - & - & - & + & - \\
\hline HPSI 4 & DPS2 & - & + & - & - & - & + & - \\
\hline & & $\begin{array}{l}* \mathrm{~W} \\
\dagger \mathrm{D} \\
\ddagger \mathrm{D}\end{array}$ & $\begin{array}{l}\text { type is d } \\
\text { oid } \gamma \mathrm{s} 20> \\
\text { oid } \gamma \mathrm{sI}_{3}>\end{array}$ & nated & atant & & & \\
\hline
\end{tabular}

and temperature resistance when a radiation-sensitive, temperature-resistant haploid was fused with a radiation-resistant, temperature-sensitive haploid.

We present here the results of genetic analysis of two radiation-sensitive mutations based on this method of diploid selection.

\section{METHODS}

Maintenance of stocks. Dictyostelium discoideum stocks were carried on agar plates in association with Escherichia coli $\mathrm{B} / \mathrm{r}$ at $23{ }^{\circ} \mathrm{C}$ as described previously (Deering et al., 1970).

Strains. Strain NC4 was the gift of Dr M. Sussman. Radiation-sensitive strains $\gamma \mathrm{s} 13$ and $\gamma$ S20 were isolated from NC4 after mutagenesis with $N$-methyl- $N^{\prime}$-nitro- $N$-nitrosoguanidine (Deering et al., 1970). Strain $\mathrm{NC}_{4}$ has a $10 \%$ survival dose $\left(D_{10}\right)$ of $300 \mathrm{krad}$ for ${ }^{60} \mathrm{Co}$ gamma rays and a $D_{10}$ value of $150 \mathrm{~J} \mathrm{~m}^{-2}$ for $254 \mathrm{~nm}$ u.v. radiation. Respectively, the $D_{10}$ values for $\gamma \mathrm{SI} 3$ are $4 \mathrm{krad}$ and $2 \mathrm{~J} \mathrm{~m}^{-2}$, and for $\gamma \mathrm{s} 20$, II $\mathrm{krad}$ and $7 \mathrm{~J} \mathrm{~m}^{-2}$.

Strain XMI was the gift of S. J. Free (Stanford University). This strain was a cycloheximideresistant (cycAI), white (whi), acriflavine(methanol)-resistant (acr $A I$ ), temperature-sensitive $\left(\operatorname{tsg} D_{I 2}\right), \alpha$-mannosidase-I-negative ( $\left.m a n A I\right)$ segregant selected from a diploid of $\mathrm{x} 9$ with a temperature-sensitive strain derived from the $\alpha$-mannosidase-I-negative strain MI (Free \& Loomis, I974; Free, Schimke \& Loomis, I976). The $\alpha$-mannosidase-I mutation has recently been mapped on linkage group VI (Free et al., I976).

Diploids DPSI and DPS2 were isolated from crosses of XMI with $\gamma \mathrm{s} 20$ and $\gamma \mathrm{SI} 3$, respectively. These diploids allowed the radiation-sensitive mutations to be mapped against linkage groups I, II and VI.

These strains, and segregants derived from DPSI and DPS2, are described more fully in Table I.

Diploid formation and selection. A modification of the technique of Williams, Kessin \& Newell $(1974 b)$ was used. The hapoids to be fused were incubated in a one to one ratio, at a total of $\mathrm{IO}^{7}$ amoebae $\mathrm{ml}^{-1}$, for $\mathrm{I} 7 \mathrm{~h}$ in $40 \mathrm{~mm}$-phosphate buffer [containing (per litre) $0.5 \mathrm{~g}$ $\left.\mathrm{MgCl}_{2} \cdot 6 \mathrm{H}_{2} \mathrm{O}, \mathrm{I} \cdot 5 \mathrm{~g} \mathrm{NaHPO}_{4}, 4 \mathrm{~g} \mathrm{KH}_{2} \mathrm{PO}_{4}, \mathrm{I} \cdot 5 \mathrm{~g} \mathrm{KCl} ; \mathrm{pH} 6 \cdot 4\right]$ with streptomycin sulphate (B grade, Calbiochem; $500 \mu \mathrm{g} \mathrm{ml}^{-1}$ ). A portion of the suspension (Io ml) was incubated at $23{ }^{\circ} \mathrm{C}$ in a $50 \mathrm{ml}$ Erlenmeyer flask with reciprocal shaking at 80 cycles $\mathrm{min}^{-1}$. Clumps of cells 
which formed under these conditions were mechanically disaggregated. To select the diploid when one parental strain was radiation-sensitive, temperature-resistant and the other radiation-resistant, temperature-sensitive, the disaggregated cells were u.v.-irradiated $\left(254 \mathrm{~nm} ; 20 \mathrm{~J} \mathrm{~m}^{-2}\right)$ before plating $3 \times 10^{5}$ cells per plate at the restrictive temperature, $27^{\circ} \mathrm{C}$. After 3 to 5 days, plaques appeared on the plates: these were the progeny either of diploids or of survivors of the radiation-sensitive strain, or of revertants of the radiation-sensitive or temperature-sensitive strain. Diploids were distinguished on the basis of spore colour, spore size, temperature resistance and ability to segregate drug-resistant segregants. To isolate DPSI, the vegetative cells were washed from several of these plates, pooled, u.v.irradiated again $\left(40 \mathrm{~J} \mathrm{~m}^{-2}\right.$ ) and replated at $2 \times 10^{4}$ per plate for incubation at $27^{\circ} \mathrm{C}$; almost all of the plaques appearing after the second irradiation were diploid. Since $\gamma \mathrm{sI} 3$ had a lower survival at $20 \mathrm{~J} \mathrm{~m}^{-2}$ than had $\gamma \mathrm{s} 20$, a single $20 \mathrm{~J} \mathrm{~m}^{-2}$ irradiation was sufficient to select against the radiation-sensitive parent; hence DPS2 was isolated from a plaque which appeared after the initial u.v. irradiation.

Selection of haploid segregants. Haploids were selected from the heterozygous diploids by plating $10^{5}$ diploid spores on plates containing $2 \%(\mathrm{v} / \mathrm{v})$ methanol (Baker): the frequency of haploidization was $5 \times \mathrm{IO}^{-4}$ (Williams, Kessin \& Newell, 1974a). Plaques appearing after 4 to 5 days were transferred with sterile toothpicks to agar plates which had been spread with a lawn of $E$. coli $\mathrm{B} / \mathrm{r}$.

Characterization of segregants. Segregants were allowed to grow for 3 to 4 days after isolation in order to obtain both vegetative and developing cells for use in screening. To screen for temperature resistance, cycloheximide resistance and radiation resistance, vegetative cells from the edge of the plaque were removed with a sterile loop and suspended in distilled water $\left(0^{\cdot} 15 \mathrm{ml}\right)$. This gave suspensions of about $2 \times 10^{6}$ cells ml-1 as determined on a model B Coulter Counter (Coulter Electronics). A drop of the suspension was removed with a sterile wire loop and touched to the surface of an agar plate. Normally suspensions from 12 plaques were spotted to each plate in a three by four array. This procedure applies about $\mathrm{IO}^{3}$ to $\mathrm{IO}^{4}$ cells per spot. Plates for testing cycloheximide resistance contained cycloheximide $\left(500 \mu \mathrm{g} \mathrm{ml}^{-1}\right)$ and were spread with a lawn of E. coli $\mathrm{B} / \mathrm{r}$. Plates for testing temperature resistance were also spread with bacteria before spotting. Resistant segregants formed a plaque by clearing the bacterial lawn whereas sensitive segregants did not. The spots remained visible even if the segregant was sensitive.

To screen for radiation resistance, plates were spotted and irradiated with u.v. radiation (50 $\mathrm{J} \mathrm{m}^{-2}$ ) or gamma rays (I00 krad for DPSI segregants, $40 \mathrm{krad}$ for DPS2 segregants), and then a drop of $E$. coli $\mathrm{B} / \mathrm{r}$ suspension $\left(5 \times 10^{9}\right.$ cells $\left.\mathrm{ml}^{-1}\right)$ was added to each spot from a tuberculin syringe. Control plates were spotted with suspensions of slime mould and bacterial cells but were not irradiated. Resistant segregants formed clear plaques within the bacterial lawns on both the control and the irradiated plates whereas sensitive segregants formed clear plaques only on the unirradiated control plates. This procedure allowed the screening of radiation resistance without affecting the bacteria. If the bacteria were spread or spotted before irradiation then the lag in their growth caused by the irradiation was sufficient to allow even the sensitive segregants to form a clear area, since the sensitive amoebae continued to consume bacteria for a period of time after irradiation, but before death.

The results of a typical spot test for segregants of diploid DPSI are presented in Fig. I. When the parental radiation-resistant strain XMI was screened for radiation resistance using a spot test, the results were similar to those for the radiation-resistant segregants (Fig. I). The parental radiation-sensitive strains $\gamma \mathrm{SI} 3$ and $\gamma / \mathrm{s} 20$ gave results similar to those for the radiation-sensitive segregants. 


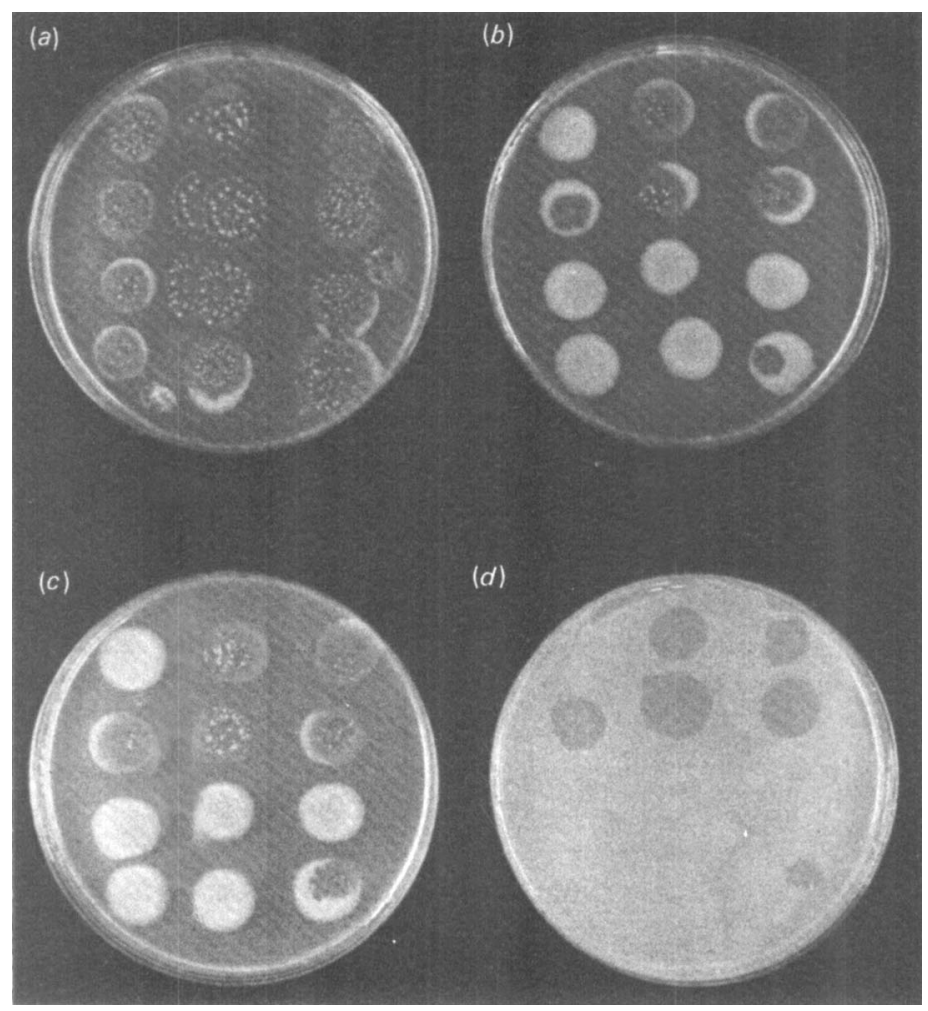

Fig. I. Typical result of spot tests with methanol-resistant segregants of DPSI : $(a)$ unirradiated control; (b) irradiated with $254 \mathrm{~nm}$ u.v. radiation, $50 \mathrm{~J} \mathrm{~m}^{-2}$; (c) irradiated with ${ }^{60} \mathrm{Co}$ gamma rays, $100 \mathrm{krad}$; and $(d)$ containing cycloheximide $\left(500 \mu \mathrm{g} \mathrm{ml}^{-1}\right)$. Resistant segregants form clear plaques within the bacterial lawns on both the control and test plates whereas sensitive segregants form plaques only on the control plates.

Since $\alpha$-mannosidase-I is a developmentally regulated enzyme (Loomis, 1970), the segregants were screened for $\alpha$-mannosidase-I activity by transferring developing cells from each segregant plaque to the tube containing the vegetative cell suspension from the same plaque. This was done to conserve equipment and reduce the time required to screen large numbers of segregants; the vegetative cells had no effect on the assay. The presence of the enzyme was determined using $p$-nitrophenyl- $\alpha$-D-mannopyranoside (Calbiochem) as described by Free et al., (1976).

Spore sizes were determined by the method of Sackin \& Ashworth (I969) using a model B Coulter Counter. Spore colours were determined either from the unirradiated control plate for the radiation-resistance test or from the plate on which the segregant was grown before screening.

Irradiation. U.v. irradiation at $254 \mathrm{~nm}$ was from a germicidal lamp at fluences of 0.3 to $2.5 \mathrm{~J} \mathrm{~m}^{-2}$. The incident intensity was measured with an International Light IL254 germicidal photometer or by a calibrated photovoltaic cell (Jagger, I96I). For survival curves and for isolating the diploids, vegetative cells were washed from plates after growing in association with $E$. coli $\mathrm{B} / \mathrm{r}$. For u.v. irradiation, the bacteria were removed by differential centrifugation at $175 \mathrm{~g}$ and washed three times with phosphate-buffered saline (PBS) (Deering et al., 1970). Cells were resuspended at $2 \times 10^{6} \mathrm{ml}^{-1}$ in PBS. Cell counts were determined with either a haemocytometer or Coulter Counter. The cell suspension $(5 \mathrm{ml})$ was irradiated in a $90 \mathrm{~mm}$ 


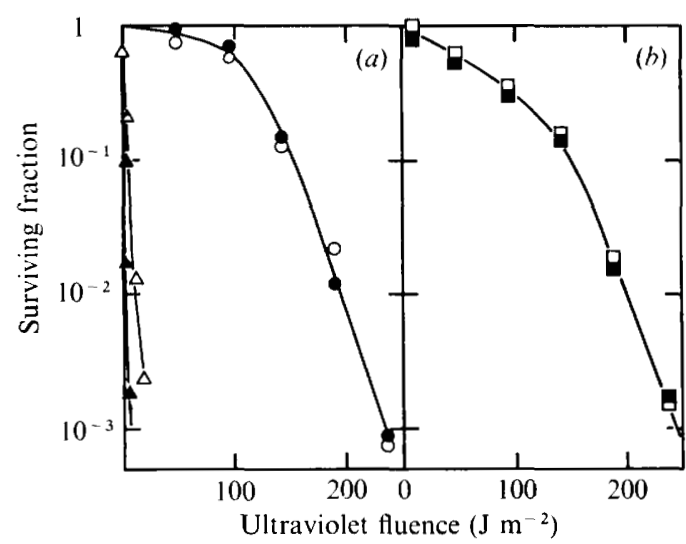

Fig. 2

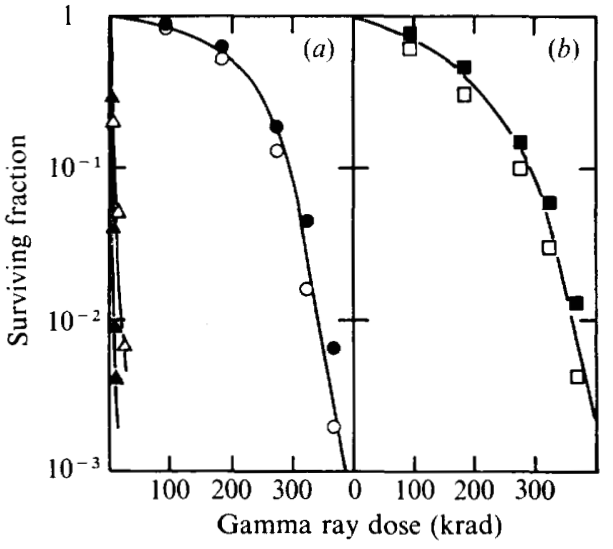

Fig. 3

Fig. 2. Survival curves, after irradiation with $254 \mathrm{~nm}$ u.v. radiation, of $(a)$ parental haploids NC4

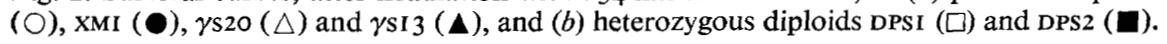

Fig. 3. Survival curves after irradiation with ${ }^{60} \mathrm{Co}$ gamma rays. Symbols as in Fig. 2.

glass Petri dish, and was rotated at $80 \mathrm{rev} . \mathrm{min}^{-1}$ during irradiation. The correction factor in absorption for volume irradiation under these conditions was $5 \%$ (Morowitz, I950).

Irradiation with ${ }^{60} \mathrm{Co}$ gamma rays was at a dose rate of $24 \mathrm{krad} \mathrm{min}^{-1}$ in a ${ }^{60} \mathrm{Co}$ Gammacell 200 (Atomic Energy of Canada) as described by Deering et al. (1970).

The cell suspensions were plated with $E$. coli $\mathrm{B} / \mathrm{r}$ as described previously (Freim \& Deering, 1970). Plaques appeared as clear areas in the bacterial lawn after 2 to 7 days incubation at $23^{\circ} \mathrm{C}$ and were counted daily.

When screening the segregants for u.v. resistance, plate surfaces were exposed to $50 \mathrm{~J} \mathrm{~m}^{-2}$; when screening for resistance to gamma rays, the plates were placed in the ${ }^{60} \mathrm{Co}$ source and irradiated with I00 krad for DPSI segregants and $40 \mathrm{krad}$ for DPS2 segregants.

\section{RESULTS}

Genetic analyses of two radiation-sensitive mutants, $\gamma \mathrm{s} 20$ and $\gamma \mathrm{SI} 3$, were performed using diploids isolated on the basis of simultaneous u.v. and temperature resistance. These mutations have been designated $\operatorname{radA} 20$ and $\operatorname{radBI} 3$, respectively.

Survival curves following u.v. and ${ }^{60} \mathrm{Co}$ gamma irradiation for the parental haploids and heterozygous diploids are presented in Figs 2 and 3. The radiation-sensitive mutations are recessive since the diploids showed similar, though not identical, survival curves to those of the wild-type resistant parental strain after irradiation with either u.v. or gamma rays. The shoulders on the diploid survival curves were lower than those of the wild-type parent but the $D_{10}$ values of the diploids were approximately the same as those of the wild-type parent. The recessive nature of the radiation-sensitive mutations was a necessary condition for the isolation of the heterozygous diploids on the basis of simultaneous u.v. and temperature resistance from a mixture of radiation-sensitive, temperature-resistant and radiation-resistant, temperature-sensitive haploids.

Both diploids were formed by crossing a radiation-sensitive strain with XMI, a cycloheximide-resistant, white, acriflavine(methanol)-resistant, temperature-sensitive, $\alpha$-mannosidaseI-negative haploid. This allowed linkage groups I (cycAI), II (whi, acrAI, tsg DI2), and 
Table 2. Linkage analysis of methanol-resistant segregants of DPS I

\begin{tabular}{|c|c|c|c|c|c|c|}
\hline Linkage group & ... & I & & II & & VI \\
\hline$\gamma \mathrm{s} 20$ & $\operatorname{rad} A 20$ & + & + & + & + & + \\
\hline & + & $c y c A I$ & whi & acrAI & $t s g D I 2$ & $\operatorname{nan} A I$ \\
\hline
\end{tabular}

(II) white, acriflavine(methanol)-resistant, temperature-sensitive

(I) $\overbrace{\text { cycloheximide-sensitive }}$ cycloheximide-resistant

(VI) $\alpha$-mannosidase-1 $\quad \alpha$-mannosidase- 1

$\overbrace{\text { positive }}^{\text {negative }} \overbrace{\text { positive }}^{\text {No. of }} \begin{gathered}\text { Negative } \\ \text { segregants }\end{gathered}$

radiation-resistant radiation-sensitive
0
28
0

47
58

33
91

75

166

39

205

Table 3. Linkage analysis of methanol-resistant segregants of DPS2

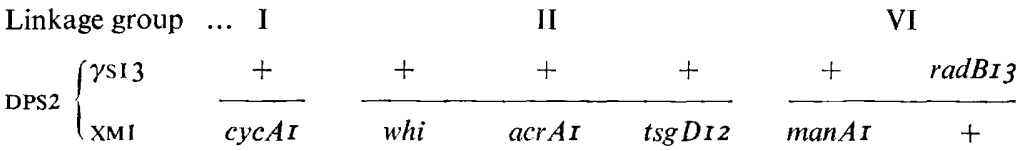

(II) white, acriflavine(methanol)-resistant, temperature-sensitive

(I) cycloheximide-sensitive cycloheximide-resistant

(VI)

$\overbrace{\text { positive }}^{\alpha \text {-mannosidase-I }}$

radiation-resistant radiation-sensitive

$\begin{array}{rr}0 & 64 \\ 5 \mathrm{I} & 0\end{array}$

$\overbrace{\text { positive }}^{\alpha \text {-mannosidase-I }}$

o

67
42

0
No. of segregants

I06

I 8

224

97

32 I

VI ( $\operatorname{manAI})$ to be mapped. The presence of the recessive drug-resistance markers allowed selection of drug-resistant segregants from the diploid population (Katz \& Sussman, 1972). Selection for methanol resistance co-selected for temperature sensitivity yielding temperature-sensitive, radiation-sensitive segregants for use in future work.

The data obtained from the genetic analysis of DPSI are presented in Table 2. This diploid was isolated from a mixture of XMI and $\gamma \mathrm{S} 20$ on the basis of simultaneous u.v. and temperature resistance. Four classes of white, methanol-resistant, temperature-sensitive haploid segregants were found on selection of methanol-resistant segregants from DPSI: these were (i) cycloheximide-resistant, $\alpha$-mannosidase-I-negative, radiation-resistant; (ii) cycloheximide-resistant, $\alpha$-mannosidase-I-positive, radiation-resistant; (iii) cycloheximide-sensitive, $\alpha$-mannosidase-I-negative, radiation-sensitive; and (iv) cycloheximide-sensitive, $\alpha$-mannosi dase-I-positive, radiation-sensitive. Sensitivity to cycloheximide and radiation always segregated together in the segregants of DPSI as expected if the radiation-sensitive and cycloheximide-resistant mutations were on the same linkage group. Thus the radiationsensitive mutation from $\gamma \mathrm{s} 20$, designated $\mathrm{radA} 2 \mathrm{O}$, is linked to linkage group I. 


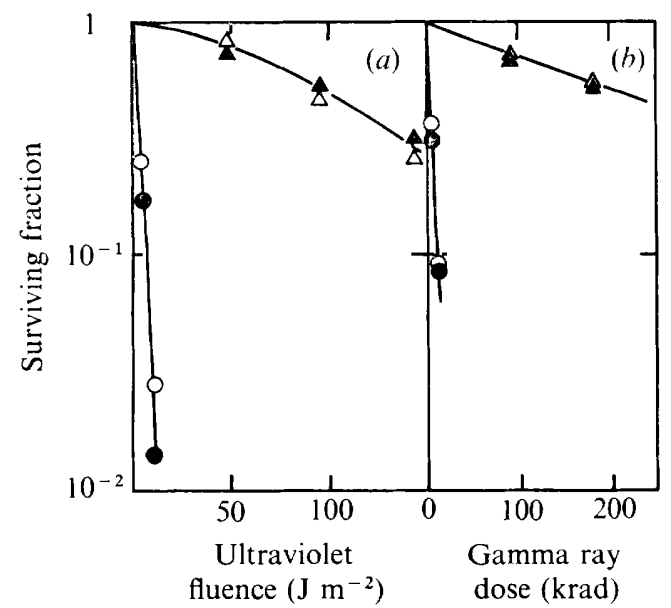

Fig. 4

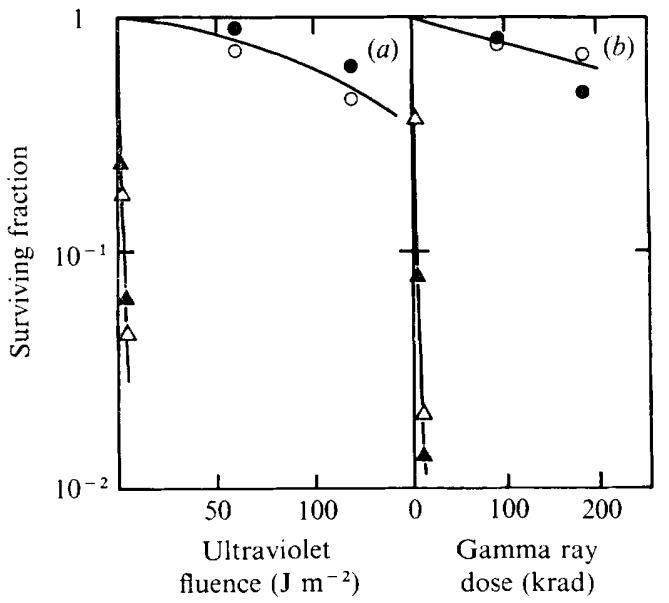

Fig. 5

Fig. 4. Survival curves of methanol-resistant segregants of DPSI after irradiation with (a) $254 \mathrm{~nm}$ u.v. radiation or $(b){ }^{60} \mathrm{Co}$ gamma rays: HPSI $(\bigcirc), \operatorname{HPS} 3(\bullet), \operatorname{HPS} 7(\triangle)$ and HPS8 $(\Delta)$.

Fig. 5. Survival curves of methanol-resistant segregants of DPS2 after irradiation with (a) $254 \mathrm{~nm}$ u.v. radiation or $(b){ }^{60}$ Co gamma rays: HPS9 $(\bigcirc)$, HPSIO $(\odot)$, HPSI I $(\Delta)$ and HPSI $4(\Delta)$.

The data obtained from the genetic analysis of DPS 2 isolated from a mixture of $\gamma \mathrm{SI} 3$ with XMI on the basis of simultaneous u.v. and temperature resistance are presented in Table 3 . Four classes of white, methanol-resistant, temperature-sensitive segregants were found on selection of methanol-resistant segregants: these were (i) cycloheximide-resistant, $\alpha$-mannosidase-I-negative, radiation-resistant; (ii) cycloheximide-resistant, $\alpha$-mannosidase-Ipositive, radiation-sensitive; (iii) cycloheximide-sensitive, $\alpha$-mannosidase-I-negative, radiation-resistant; and (iv) cycloheximide-sensitive, $\alpha$-mannosidase-I-positive, radiation-sensitive. Since the radiation sensitivity always segregated with the presence of $\alpha$-mannosidase-I activity, the radiation sensitive and $\alpha$-mannosidase-I markers must be linked. The $\alpha$-mannosidase-I marker ( $m a n A I$ ) has previously been shown to be linked to linkage group VI (Free et al., I976); thus the radiation-sensitive mutation from $\gamma \mathrm{SI}_{3}$, designated $\mathrm{radBI} 3$, is also linked to linkage group VI.

For segregants of DPSI or DPS2, in which resistance to both u.v. and gamma rays was screened on the same segregant clone, resistance or sensitivity to both agents always segregated together. This can be seen in the results of the spot tests for segregants of DPSI (Fig. I). No segregants were resistant to either u.v. or gamma rays but sensitive to the other; nor were segregants with intermediate sensitivities found. As shown in Figs 4 and 5, segregants had either the sensitivity of the sensitive parent, to both u.v. and gamma rays, or the resistance of the resistant parent to both agents.

In addition to the haploid, white, methanol-resistant, temperature-sensitive segregants, a number of methanol-resistant segregants with non-parental linkage groups II were obtained from both DPSI and DPS2. These were presumably mitotic recombinants and/or new mutations to methanol resistance or temperature resistance (Gingold \& Ashworth, I974; Katz \& Kao, 1974; Mosses, Williams \& Newell, I975). Most of them were diploid on the basis of spore size, and remained heterozygous for $\alpha$-mannosidase- $\mathrm{I}$, cycloheximide resistance and radiation resistance. These segregants included strains that were: (i) white, temperature-resistant; (ii) white, temperature-sensitive; (iii) yellow, temperature-resistant; and (iv) yellow, temperature-sensitive. The number of non-parental clones of each class varied from one selection 
of methanol-resistant segregants to another, suggesting that they were not the result of independent crossover events but were the daughters of a small number of original recombinants (Williams et al., I974a; Mosses et al., 1975). A small number of haploids (10) with a non-parental linkage group II were also isolated after non-parental clones were re-cloned following about 100 generations of growth at $23{ }^{\circ} \mathrm{C}$. These clones had a characteristic haploid spore size and apparently had arisen by a chance segregation in the non-parental, presumably diploid, clone before re-cloning. As is expected for haploids, these clones are no longer heterozygous for the unlinked cycloheximide-resistance, $\alpha$-mannosidase-I, or radiation-resistance markers.

\section{DISCUSSION}

Radiation-sensitive mutations are useful for genetic studies in $D$. discoideum as they provide new markers for defining linkage groups. Preliminary evidence using several radiation-sensitive strains other than $\gamma \mathrm{SI} 3$ and $\gamma \mathrm{s} 20$ indicates that there are at least two other mutations which lead to radiation sensitivity in $D$. discoideum. Work is in progress to determine the linkage of these mutations.

The $\operatorname{radAzo}$ and $\mathrm{radBr} 3$ mutations are recessive as are most other chromosomal markers in $D$. discoideum. Indeed, the recessive nature of these radiation-sensitive mutations was a requirement for the selection of the heterozygous diploids on the basis of radiation resistance. This selection procedure requires that the diploid be more resistant than the radiationsensitive parental strain. The strains used in this study are among the most sensitive to radiation available. They were chosen because the difference in sensitivity between the radiation-sensitive parent and the heterozygous diploid was maximal, thus making it easier to isolate the diploid and requiring the lowest radiation doses. Work is in progress to select diploids between suitably marked temperature-sensitive strains and strains with intermediate radiation sensitivities using higher selective doses and also using gamma rays in the selection procedure. It should be pointed out that the cells are not necessarily diploid at the time of the initial selective irradiation, and that the heterokaryon of a radiation-sensitive strain and a radiation-resistant strain may or may not be as resistant as the diploid eventually isolated.

The genetic analyses of $\gamma \mathrm{si} 3$ and $\gamma$ s2o have yielded useful information on the nature of the radiation-sensitive mutations in these strains. The results suggest that the radiation sensitivity is due to a single mutation in each strain. No segregants with intermediate sensitivity were found among those tested. All of the segregants had either the sensitivity of the radiation-sensitive parent or the resistance of the radiation-resistant parent. However, the possibility of a double mutation on the same linkage group cannot be excluded.

The radiation-sensitive segregants isolated will be useful in further characterization of repair of radiation damage in $D$. discoideum. The use of methanol in the selection of segregants co-selects for the $t s g D_{I 2}$ temperature-sensitive mutation. This allows the radiationsensitive mutations to be transferred into strains bearing different genetic characteristics using the standard technique of selection of diploids by temperature resistance. For example, axenic radiation sensitives have been produced using a radiation-sensitive segregant of DPS2. Such axenic strains may be useful in studies on the repair enzymes in $D$. discoideum (Deering \& Jensen, 1975). Strains can also be produced which bear multiple radiationsensitive mutations, allowing the involvement of the mutations in the same or different repair pathways to be determined. Complementation of radiation-sensitive mutations in diploid cells can also be studied enabling determination of allelism. 
We wish to thank P. C. Hanawalt, Stanford University, in whose laboratory much of this work was performed, for his co-operation. We also thank S. J. Free for the gift of strain XMI and for communicating his results before publication. In addition, we thank $\mathrm{S}$. Person, P. C. Newell, W. F. Loomis and K. Williams for their valuable comments about the manuscript.

This investigation was supported by Public Health Services Research Grant GM-I6620 from the National Institute of General Medical Sciences.

\section{REFERENCES}

Brody, T. \& Williams, K. L. (1974). Cytological analysis of the parasexual cycle in Dictyostelium discoideum. Journal of General Microbiology 82, 371-383.

DeERING, R. A. (1968). Dictyostelium discoideum: a gamma-ray resistant organism. Science, New York I62, I 289-I 290.

DeERING, R. A. (1975). Dictyostelium discoideum: a valuable eukaryotic system for repair studies. In Molecular Mechanisms for Repair of DNA, part B, pp. 58I-584. New York: Plenum Publishing Corp.

DeERING, R. A. \& Jensen, D. S. (I973). Nuclear and mitochondrial DNA synthesis in gamma ray-resistant and -sensitive slime mold amoebas. Biophysical Journal 13 (2), 780-794.

DeERING, R. A. \& Jensen, D. S. (1975). Endonuclease from Dictyostelium discoideum that attacks ultraviolet-irradiated deoxyribonucleic acid. Journal of Bacteriology I2I, I 2 I I-1 213.

Deering, R. A., Smith, M. S., Thompson, B. K. \& Adolf, A. C. (1970). Gamma-ray-resistant and -sensitive strains of slime mold (Dictyostelium discoideum). Radiation Research 43, 7 I I-728.

FreE, S. J. \& Loomis, W. F. (1974). Isolation of mutations in Dictyostelium discoideum affecting $\alpha$-mannosidase. Biochimie 56, $1525-1528$.

Free, S. J., Schimke, R. T. \& Loomis, W. F. (1976). The structural gene for $\alpha$-mannosidase-I in Dictyostelium discoideum. Genetics (in the Press).

Freim, J. O. \& DeERING, R. A. (1970). Ultraviolet irradiation of the vegetative cells of Dictyostelium discoideum. Journal of Bacteriology 102, 36-42.

GiNGOLD, E. B. \& AsHWORTH, J. M. (1974). Evidence for mitotic crossing-over during the parasexual cycle of the cellular slime mould Dictyostelium discoideum. Journal of General Microbiology 84, 70-78.

Guialis, A. \& DeERING, R. A. (1976a). Repair of deoxyribonucleic acid in ultraviolet light-sensitive and -resistant Dictyostelium discoideum strains. Journal of Bacteriology 127, 59-66.

Guialis, A. \& DeERING, R. A. (1976b). Inhibition of UV-induced DNA strand breakage in Dictyostelium discoideum by 2,4-dinitrophenol. Photochemistry and Photobiology (in the Press).

JAGGER, J. (196I). A small and inexpensive ultraviolet dose-rate meter useful in biolegical experiments. Radiation Research 14, 394-403.

KATZ, E. R. \& KAO, V. (1974). Evidence for mitotic recombination in the cellular slime mold Dictyostelium discoideum. Proceedings of the National Academy of Sciences of the United States of America 71, 40254026.

KatZ, E. R. \& Sussman, M. (1972). Parasexual recombination in Dictyostelium discoideum: selection of stable diploid heterozygotes and stable haploid segregants. Proceedings of the National Academy of Sciences of the United States of America 69, 495-498.

Khoury, A. T. \& DeERING, R. A. (I973). Sedimentation of DNA of Dictyostelium discoideum lysed on alkaline sucrose gradients: role of single-strand breaks in gamma ray lethality of sensitive and resistant strains. Journal of Molecular Biology 79, 267-284.

Loomis, W. F. (1969). Temperature-sensitive mutants of Dictyostelium discoideum. Journal of Bacteriology 99, 65-69.

Loomis, W. F. (1970). Developmental regulation of $\alpha$-mannosidase in Dictyostelium discoideum. Journal of Bacteriology I03, 375-38I.

Morowitz, H. J. (1950). Absorption effects in volume irradiations of microorganisms. Science, New York III, 229-230.

Mosses, D., Williams, K. L. \& Newell, P. C. (I975). The use of mitotic crossing-over for genetic analysis in Dictyostelium discoideum: mapping of linkage group II. Journal of General Microbiology 90, 247259.

Payez, J. F. \& DeERing, R. A. (1972). Synergistic and antagonistic effects of caffeine on two strains of cellular slime mold treated with alkylating agents. Mutation Research 16, 31 8-32I.

Payez, J. F., Deering, R. A. \& Freim, J. O. (1972). Lethal effects of alkylating agents or ultraviolet light on the gamma-ray resistant parent strain and a gamma-ray sensitive strain of the cellular slime mold Dictyostelium discoideum. Mutation Research I5, 82-85.

PONTECORVo, G. \& KäFER, E. (1958). Genetic analysis based on mitotic recombination. Advances in Genetics 9, $7 \mathrm{I}-\mathrm{IO} 4$. 
Sackin, M. J. \& Ashworth, J. M. (1969). An analysis of the distribution of volumes amongst spores of the cellular slime mould Dictyostelium discoideum. Journal of General Microbiology 59, 275-284.

SINHA, U. \& ASHWORTH, J. M. (1969). Evidence for the existence of elements of a parasexual cycle in the cellular slime mould, Dictyostelium discoideum. Proceedings of the Royal Society Br73, 53 I-540.

Williams, K. L., Kessin, R. H. \& Newell, P. C. (1974a). Parasexual genetics in Dictyostelium discoideum: mitotic analysis of acriflavin resistance and growth in axenic medium. Journal of General Microbiology 84, 59-69.

Williams, K. L., Kessin, R. H. \& Newell, P. C. (1974b). Genetics of growth in axenic medium of the cellular slime mould Dictyostelium discoideum. Nature, London 247, I42-I43. 